\title{
CF1022
}

\section{Robustness of Multistory Buildings with Masonry Infill}

\author{
F. B. Xavier ${ }^{1}$; L. Macorini²; B. A. Izzuddin, M.ASCE ${ }^{3}$ \\ ${ }^{1} \mathrm{Ph} . \mathrm{D}$ candidate, Dept. of Civil and Environmental Engineering, Imperial College London, South \\ Kensington Campus, London SW7 2AZ, U.K. E-mail: francisco.xavier11@imperial.ac.uk \\ ${ }^{2}$ Lecturer, Dept. of Civil and Environmental Engineering, Imperial College London, South \\ Kensington Campus, London SW7 2AZ, U.K. E-mail: 1.macorini@imperial.ac.uk \\ ${ }^{3}$ Professor of Computational Structural Mechanics, Dept. of Civil and Environmental \\ Engineering, Imperial College London, South Kensington, London SW7 2AZ, U.K. \\ (corresponding author). E-mail: b.izzuddin@imperial.ac.uk
}

\begin{abstract}
This paper investigates the influence of unreinforced masonry panels on the robustness of multistorey buildings under sudden column loss scenarios. A recently developed multi-level framework is employed to evaluate the resistance to progressive collapse under such scenarios, which is applied here at storey level allowing for the resistance of the floor system and the infill panels. The response of various structural components under pushdown deformation is obtained using high-fidelity finite element analysis, where an accurate mesoscale description is utilised for the masonry infill, elasto-plastic beam-column elements are used for the floor system, and component-based nonlinear mechanical models are employed for the joints. This methodology is applied to a 7-storey composite steel-concrete benchmark building, where it is established that the use of masonry infill panels for exterior cladding can considerably increase progressive collapse resistance, even in the case of perforated walls. Furthermore, the results indicate that the maximum dynamic deformations under sudden column loss are relatively small due to the
\end{abstract}


significant resistance of the infill, which is particularly relevant when considering the retrofitting of structures affected by column loss.

Keywords: Robustness Assessment, Progressive Collapse, Masonry Infill, Mesoscale Models

\section{Introduction}

Unreinforced masonry (URM) walls are widely employed as interior and exterior claddings in building structures. In practical design, masonry cladding panels are assumed as non-structural components, thus their contribution is usually not taken into account in evaluating the resistance of the main structural system. However, because of their inherent high planar stiffness and strength, they may strongly influence the response of building structures when subjected to extreme loading. Damage observations after recent earthquakes revealed that the influence of URM infill panels was in some cases beneficial while in others detrimental to the overall structural performance (Mosalam \& Günay, 2014). Depending on many factors ranging from relative frame-infill mechanical properties to geometrical layout, masonry panels may either enhance building resistance or trigger unexpected brittle failure modes. Unlike global seismic behaviour, the contribution of masonry infill under severe localized damage is typically seen as beneficial, as pointed by Cormie et al. (2009) and Smith et al. (2010) with regards to blast loading or Tiago \& Julio (2010) in the case of land slide impact. In these scenarios, masonry panels usually enable the activation of alternative paths for gravity loads upon sudden removal of primary structural members.

This paper investigates the performance enhancement of masonry infill in the context of building robustness assessment, emphasising the possible implications for rational/economic design and retrofitting recommendations ensuing from explicitly modelling masonry infill as an integrated structural component. 
Despite the lack of globally agreed definition and quantification procedure, the robustness of constructed facilities is commonly addressed in structural design by using specific detailing rules to safely redistribute loads from damaged components to adjacent unaffected parts. Current code provisions, including Eurocode 1 (ECS, 2006) and Unified Facilities Criteria (DoD, 2009) to cite a few, support this approach aimed at reducing the sensitivity to initial local damage regardless of the nature of the triggering event, such that any ensuing damage is not disproportionate to the original cause. In the context of local damage scenarios consisting of sudden column loss, robustness can be directly related to the ability of the structure above to withstand the maximum dynamic deformations without failure, in which case progressive collapse is avoided, an approach that has been extensively employed by several researchers (Xu \& Ellingwood, 2011; Khandelwal \& El-Tawil, 2011). In the present work, the positive influence of URM infill on reducing the structural sensitivity to column loss is demonstrated by the fact that such elements display a substantial contribution to structural resistance, which is also achieved at relatively small deformations leading to reduced permanent damage. Nonetheless, the previous lack of a single methodology capable of coherently quantify the ability of a structure to avert disproportionate spread of damage has restricted the application of performance-based robustness assessment in practice.

In this paper, the robustness of a multi-storey steel building with exterior infill frames and composite floors is quantified for sudden column loss scenarios using the progressive collapse assessment framework recently developed by Izzuddin et al. (2008). This framework accounts effectively for the influence of structural redundancy, ductility, dynamic effects and energy absorption capacity in a unified manner. In particular, when employed in its multi-level form, this framework allows progressive collapse resistance to be determined by the assemblage of 
contributions from individual structural components, delivering a method especially suited for assessing the relative importance of masonry infill compared to other commonly considered structural components.

Preliminary work utilising multiple-strut models to represent exterior cladding (Farazman et al., 2013) provided initial results where a significant potential enhancement in robustness was identified. Nevertheless, the use of this simplified representation for the infill panels and their interaction with the main frame does not enable an accurate representation of the complex phenomena governing the response of the overall system response under sudden column loss (Fig. 1). In this work, a more advanced numerical strategy is adopted in which a detailed 3D mesoscale description is considered for masonry components, where units and mortar joints are modelled separately, while elasto-plastic beam-column elements are employed for the main frame system. Further accuracy stems from the consideration of realistic mechanical componentbased models to represent the response of steel-concrete composite joints under extreme loading (Vlassis et al., 2008; Zolghadr Jahromi et al., 2013). This numerical strategy, which benefits from the use of multi-dimensional partitioned modelling allowing for parallel computation, allows high-fidelity simulations of infill frames subjected to pushdown deformations.

In the following sections, a review of the main steps and characteristics of the progressive collapse assessment framework is presented, highlighting the necessary extensions to include masonry infill contribution. This is followed by an overview of the advanced modelling approach used for masonry infill (Macorini \& Izzuddin, 2014) with special focus on the multi-dimensional partitioning allowing proper coupling of masonry mesoscale (3D) and structural frame elements (beam/column and component-based joint models). Finally, a composite steel-concrete multistorey benchmark building is considered under peripheral sudden column loss, where significant 
practical conclusions are made in relation to the potential influence of masonry infill on structural robustness.

\section{Review of Robustness Assessment Framework}

The approach introduced by Izzuddin et al. (2008) for robustness assessment under sudden column loss is employed to establish a Robustness Limit State beyond which local damage develops into disproportionate global collapse (Izzuddin, 2010). This provides an eventindependent framework to assess structural survivability when a member is severely damaged by direct action, while circumventing the need for explicit simulation of the actual event, which is often complex and computationally demanding. In general when using this approach, conservative results are obtained compared to direct modelling of blast loading on framed structures (Gudmundsson \& Izzuddin, 2010). Moreover, compliance with current codified robustness provisions (ECS, 2006; DoD, 2009) in relation to unforeseen extreme events is guaranteed. This is particularly relevant when extending alternate load path (ALP) methodologies to the specific case of framed structures with URM infill walls using the progressive collapse assessment framework described below. In this respect, the presence of URM infill is effectively regarded as a fully integrated structural constituent. This means that the URM infill, which is confined by the surrounding frame elements (e.g. beams and columns), can be directly included in the ALP method enabling alternative load paths, which are usually disregarded when URM infill walls are not explicitly modelled. Such a modelling strategy is in agreement with the code prescribed guidelines which allow for different levels of structural idealization and modelling sophistication, ranging from linear static to advanced nonlinear dynamic analysis. As demonstrated in the application example presented in this work, nonlinear frame-infill interaction is critical for a realistic representation of the pushdown response, 
indicating that simple linear simulations allowed by current codes might induce unrealistic robustness assessments. Furthermore, the proposed approach is mainly intended to assess the actual capacity of URM infill under sudden column loss by means of a sound mechanical model, which can be used in future research to generate simplified guidance for robustness design allowing for the contribution of URM infill.

Sudden column loss is conceptually equivalent to an instantaneous application of a gravity load on the affected part of the structure which induces a response governed by a dominant generalized deformation mode (Fig. 2). This assumption, which was extensively verified in previous work (Vlassis, 2007), enables the problem to be effectively idealized as a nonlinear SDOF system. Taking advantage of such a simplification, the maximum dynamic response is obtained from energy balance considerations, bypassing cumbersome nonlinear dynamic analysis. The assessment framework encompasses three main steps: $i$ ) nonlinear static analysis disregarding the removed column, ii) simplified dynamic response and iii) ductility assessment (Izzuddin et al., 2008). At the last step, the direct comparison between ductility supply and demand provides a single rational measure of robustness, where the influence of redundancy, ductility and energy absorption are combined leading to a ductility-centred procedure (Izzuddin et al., 2008; Izzuddin \& Nethercot, 2009; Izzuddin, 2010).

\section{Multi-level Implementation with Masonry Infill}

Based on the assumption of a dominant deformation mode, and depending on the degree of architectural and loading regularity, the nonlinear static response is obtained at different levels of structural idealisation ranging from the simulation of multi-storey sub-structures with appropriate boundary conditions to single element analysis (Fig. 3). In the latter case, individual contributions are assembled utilising appropriate compatibility factors related to the relevant 
deformation mode. Different levels of modelling sophistication are easily embedded in this approach. This is equally suitable for initial design assessment and advanced verifications for retrofitting of existing facilities, where enhancing the order of idealisation leads to higher progressive collapse resistance. This was pointed out by Zolghadr Jahromi et al. (2013) where different modelling techniques were adopted to represent the contribution of composite floors in the progressive collapse assessment of a building structure. It was shown that higher progressive collapse resistance is obtained when using detailed modelling for the composite floor (Fig. 3d) compared to a more simplified grillage model where the individual beams are assembled according to a specific deformation mode (Fig. 3e).

The contribution of masonry infill is introduced at this stage of the assessment framework. In general the actual distribution of gravity loads is difficult to establish a priori due to geometric and stiffness changes occurring as deformation progresses into large displacements domain. Nevertheless, under the assumption of the dominant deformation mode sketched in Fig. 4, a relationship between the incremental work done by the uniformly distributed floor load $P_{F l o o r}$ and the energy absorbed by the floor system $W$ can be established as:

$\delta W\left(U_{s}\right)=\alpha P_{F l o o r} \delta U_{s}$

where $u_{s}$ is the generalised SDOF displacement, and $\alpha$ is a work related factor derived in Izzuddin et al. (2008). Manipulation of (1) leads to the generalised nonlinear static response of the floor system:

$P_{\text {Floor }}=\frac{1}{\alpha} P_{\text {Floor }}^{\prime}$ 
where $P_{F l o o r}^{\prime}$ is the equivalent floor nonlinear static resistance corresponding to $u_{s}$ computed either using detailed floor models or simplified grillage assemblages (Zolghadr Jahromi et al., 2013). A similar procedure is employed to derive the nonlinear static response of the masonry panels, as shown in Fig. 4, where each infill is loaded at the top and the bottom to reproduce uniformity of floor loading. As opposed to Farazman et al. (2013), the response of masonry panels is obtained using a numerical model with a realistic representation of the interaction between the infill and the frame. The contribution of masonry infill is then extracted by simply subtracting the resistance of the peripheral bare frame under the same deformation mode. The generalised nonlinear static response of masonry infill is thus obtained as:

$P_{\text {Panel }}=\frac{1}{\alpha} P_{\text {Panel }}^{\prime}$

where $P_{\text {Panel }}^{\prime}$ represents the equivalent nonlinear static resistance of a single set of adjacent panels corresponding to $u_{s}$. Assuming uniformity of structure over the height of the multi-storey building, the total system nonlinear static resistance is obtained as the sum of individual contribution of floors and infill panels:

$$
P_{\text {Total }}=n P_{\text {Floor }}+(n-1) P_{\text {Panel }}
$$

where $n$ is the number of floors above the removed column and assuming complete loss of the masonry panels adjacent to the removed column, as illustrated in Fig. $3 a$. Although robustness assessment can be applied at the whole structure level, as implied by (4), assessment can also be 
equally undertaken for a single representative floor, in which case the contribution of masonry infill must be adjusted by a factor $\gamma$.

$\gamma=\frac{(n-1)}{n}$

Clearly, this arises from (4) by dividing $P_{\text {Total }}$ by the number of affected floors. Moreover, the factor $\gamma$ allows a simple evaluation of the infill panel contribution as the number of affected floors and masonry walls is varied. This is highlighted in the case study presented later.

\section{Simplified Dynamic Assessment}

The second step in the assessment framework obtains the maximum dynamic response as a transformation of the nonlinear static response using energy balance considerations. With reference to Fig. 5, the maximum dynamic displacement induced by sudden application of $\lambda_{n} P_{0}$ is achieved when the absorbed energy (depicted as the area under $P$ - $u$ curve in Fig. 5) is equal to the work done by $\lambda_{n} P_{0}$ over displacement $u$. This condition occurs exactly at displacement $u_{d, n}$. Applying this energy balance at different load levels $\lambda_{n}$, a pseudo-static response curve is obtained (Fig. 5), which directly provides the maximum dynamic displacement corresponding to sudden column loss under applied loading $\lambda_{n} P_{0}$. Analytically, the pseudo-static curve is obtained as (Izzuddin et al., 2008):

$P_{n}=\lambda_{n} P_{0}=\frac{1}{u_{d, n}} \int_{0}^{u_{d, n}} P d u$

where $P$ inside the integral represents the nonlinear static resistance. The validity of this simplified procedure when compared to full nonlinear dynamic numerical results was confirmed 
by Vlassis (2007). Also of practical relevance, the overall pseudo-capacity of a structural system can be assembled from contributions of individual components in a similar manner to the procedure described above for nonlinear static response (Izzuddin et al., 2008). Another practical advantage of the simplified dynamic procedure when compared to direct dynamic computations is that there is no need to explicitly define time steps for the application of loads and removal of elements, as these parameters induce variations in the obtained results.

Finally, the Robustness Limit State is established trough comparing the ductility demand arising from the maximum dynamic response to the ductility limit. This overcomes the drawbacks of standard load-factor procedures as noted by Izzuddin \& Nethercot (2009) and Izzuddin (2010). Focusing on the example of Fig. 5, the limit state is equivalently obtained from comparing the applied gravity load $P_{0}$ against the maximum pseudo-static capacity $P_{f}$ available within the allowed ductility limit $u_{f}$. This ductility limit explicitly accounts for the ductility of individual components and possible incremental failure modes. In the example of Fig. 5, the nonlinear static response is monotonically increasing meaning that the maximum pseudo-static capacity is achieved at the maximum available ductility $u_{f}$. However, the presence of infill panels is known to induce a considerably high maximum static resistance which is achieved at small deformations and is followed by a degradation of strength due to the quasi-brittle nature of URM. This renders the maximum pseudo-static capacity not necessarily associated with the structural ductility limit. Nonetheless, even if masonry panels are idealised as perfectly brittle with zero residual strength, as for instance assumed by Mosalam \& Günay (2014), the direct application of (6) reveals that a residual pseudo-static contribution still exists:

$$
P_{\text {Panel, res }}=\frac{P_{\text {Panel, } \text { max }} \cdot u_{\text {Panel, } \text { max }}}{u_{\text {res }}} \quad \text { for } \quad u_{\text {Panel, } \text { max }}<u_{\text {res }} \leq u_{f}
$$


where $P_{\text {Panel, } \max }$ is the panel maximum pseudo-static capacity immediately before URM failure (at $u_{\text {Panel, } \max }$ ), and $u_{r e s}$ is the maximum dynamic displacement considered for ductility assessment, limited by $u_{f}$. To further illustrate the residual influence induced by instantaneous infill removal, the idealised response of three URM panels with increasing static softening response (including perfectly brittle case, i.e., instantaneous loss) is presented in Figure 6. It can be observed that even for the perfectly brittle case, a contribution to the pseudo-static capacity due to the dynamic nature of sudden column loss is still recorded in accordance with the derived expression (7). On the other hand, if a more gradual softening (i.e., ductile) behaviour of the URM panels is accounted for, further pseudo-static capacity enhancement is achieved as shown in Figure 6, where the maximum capacity of the overall structural system is obtained at the point where the nonlinear static curve intersects the pseudo-static curve (Izzuddin, 2009). In Figure 6, all the capacities are normalised with respect to the static capacity (similar for all the three cases) and the displacements with respect to the corresponding static deformation. As expected, because a linear initial branch is considered, the maximum pseudo-static capacity for the brittle case is half of the static one. As to the softening cases, it is seen that increasing the post-peak energy absorption capacity leads to an increment in the maximum pseudo-static capacity up to $60 \%$ of the static peak strength. This is quite significant because, despite the fact that URM displays a brittle response when acting in isolation, it can as part of a structural system continue to provide a significant contribution to the overall system pseudo-static capacity at large deflections. Moreover, the ductility of URM panels can be substantially improved by confinement provided by surrounding frame elements or, if necessary, by the use of reinforcement typically available for engineering applications. 
In summary, according to the adopted ductility-centred robustness assessment framework the global structure is reduced to a generalised SDOF problem and energy balance considerations are utilised to obtain the maximum dynamic response in a simplified manner. As a result, when the ductility supply is higher than demand associated with the maximum dynamic response, the structure is considered to withstand sudden column loss; otherwise, progressive collapse develops.

\section{Multi-Dimensional Finite Element Analysis of Infilled Frames}

To achieve the desired accuracy with regard to the phenomena depicted in Fig.1 $b$ a multidimensional numerical strategy is employed following a methodology previously applied to blast loading analysis of infilled frames (Macorini \& Izzuddin, 2014). In this section, only the main features of the modelling scheme are presented for the sake of completeness.

\section{Mesoscale Model for Unreinforced Masonry Panels}

The nonlinear 3D mesoscale framework developed by Macorini \& Izzuddin (2011) is employed where brick units are modelled by 3D solid brick finite elements and mortar joints are discretely accounted for by means of zero-thickness 2D interfaces, as illustrated in Fig. 7. Such a formulation delivers a general methodology for infill panels enabling the representation of any arrangement for brick-masonry accounting for both the in-plane stacking mode and the throughthickness geometry. Additionally, it allows the investigation of both the in-plane and the out-ofplane response of unreinforced masonry panels. Potential cracks propagating through brick units are captured by interface elements inserted between solid elements, bearing in mind that the number of solid elements used to represent a single brick depends on the required accuracy. In order to represent the actual behaviour of brick-masonry under high compressive stresses, the 
mesoscale framework has been recently extended by the authors to account for brick-mortar interaction (Xavier et al., 2013). This is achieved by enhancing the nonlinear interface element local kinematics in order to accommodate triaxial effects, capturing the influence of brick-mortar distinct deformational characteristics without employing computationally demanding detailed microscale analysis. Interface elements are then combined with multi-surface cohesive material models based on fracture mechanics concepts, thus providing an objective simulation of the softening behaviour associated with unreinforced masonry damage response (Macorini \& Izzuddin, 2011).

\section{Multi-dimensional Scheme for Frame/Infill Coupling}

The multi-dimensional scheme presented in Jokhio (2012) is used to efficiently couple the above 3D masonry model with nonlinear 1D beam-column finite elements. This contrasts with typical methods of analysis for infilled frames, where structural members are modelled with the same dimensional order of the infill masonry panels (i.e., continuum 2D or 3D solid finite elements), thus increasing the computational burden. An illustration of the dimensional coupling is shown in Fig. 8, where the frame/infill interface is modelled using the same interface finite element utilised for mortar joints, enabling cracking, friction and crushing to be accurately captured by means of advanced cohesive models. The outer surface of the frame/infill interface is then compatibly connected to the beam/column elements following the master-slave procedure described in Jokhio (2012). This enables an effective coupling of structural elements with rotational DOFs with continuum solid elements characterised by only translational freedoms.

Moreover, coupling masonry mesoscale models with a simplified frame formulation also facilitates the incorporation of component based mechanical models for structural joints in a 
computationally efficient fashion combining nonlinear springs, contact elements and rigid links. As shown in the subsequent case study, realistic joint models are very important in capturing the nonlinear response of steel frames with masonry infill under column loss scenarios, as they allow deformations induced by stiff masonry panels to be accommodated by the surrounding frame.

Further computational enhancement is achieved by parallel computing procedures associated with dual partition super-elements (Jokhio \& Izzuddin, 2013), as demonstrated in previous applications to unreinforced masonry structures (Macorini \& Izzuddin, 2013). The numerical strategy described above was implemented in the nonlinear finite element code ADAPTIC (Izzuddin, 1991), which is employed in the numerical simulations presented in the following section.

\section{Application to a Multi-storey Building}

\section{Overview of Case Study}

The effective contribution of unreinforced masonry infill towards progressive collapse resistance of a 7-storey steel-concrete composite building (Fig. 9a) is evaluated by coupling the ductilitycentred robustness assessment framework with the nonlinear numerical strategy previously described. This benchmark building has been extensively analysed disregarding the presence of any masonry panels (Vlassis et al., 2008; Zolghadr Jahromi et al., 2013) and also accounting for exterior cladding by means of simplified strut models (Farazman et al., 2013). Only the peripheral sudden column loss scenario is addressed in the current analysis. A plan of the bays

directly affected and a sketch of the edge beam to peripheral column connection are detailed in Fig. $9 b$ and $9 c$, respectively.

As the main point of the present manuscript is the extension of the progressive collapse assessment framework to accommodate the presence of URM infill and subsequently to assess 
the potential gain in robustness, a simple building layout is considered in order to transfer all the uncertainty in the enhanced response to the presence of such masonry elements. Towards this end, structural uniformity is assumed for all floors enabling robustness assessment to be performed at the individual floor level (Izzuddin et al., 2008) and allowing the infill contribution to be computed according to the procedure detailed above. Extension to the cases where geometric and loading uniformity do not hold over the floors is still possible although computationally more expensive, as multi-floor nonlinear models would be required to accommodate the response induced by these non-uniformities (this is also valid for non-uniform distribution of URM panels over the floors). Notwithstanding, in such cases, SDOF idealization is still a reasonable simplification as the global response under sudden column loss is effectively governed by a dominant deformation mode.

The benchmark building structure has $3.0 \mathrm{~m}$ inter-storey height and edge beams joined to the web of the external columns by partial strength connections (Fig.9c). It is assumed that these connections are still active immediately after sudden column removal, ensuring continuity between the adjacent edge beams and the transverse main beam. Possible subsequent failure is inherently captured by the component-based model. In the presented example, unreinforced masonry infill in external cladding consists of single leaf running bond solid or perforated walls with $200 \times 200 \times 400 \mathrm{~mm}^{3}$ hollow concrete masonry units bonded by $10 \mathrm{~mm}$ thick mortar head and bed joints, as considered in previous research on the blast response (Macorini \& Izzuddin, 2014). Material properties attributed to the composite frame members and mortar joint interfaces are listed in Tables 1 and 2, respectively. As to the concrete blocks, Young's modulus E=10000 MPa and Poisson's ratio $v=0.15$ are used.

\section{Review of Results without Masonry Infill}


For subsequent comparison purposes, the overall progressive collapse resistance obtained as the maximum pseudo-static capacity without masonry infill is summarized in Table 3 . The results, which were obtained employing different levels of structural detailing and idealisation, demonstrate that the application of sophisticated structural models leads to an increased computed progressive collapse resistance, where features such as membrane action in slabs which enhance the load carrying capacity are properly reproduced. The results listed in Table 3 confirm that the composite floor system is able to prevent collapse progression, where the overall capacity is limited by the ductility supply of the connection components in tension. More details are available elsewhere (Vlassis et al., 2008; Zolghadr Jahromi et al., 2013). Significant deformations (i.e. downward displacement at the lost column location) of between $300-400 \mathrm{~mm}$ are necessary to achieve the maximum capacity, thus considerable cracking/damage should be expected. This is especially relevant when considering retrofit operations.

\section{Evaluation of Single Panel Capacity}

Within the present progressive collapse assessment framework, the pseudo-static capacity for a single panel is first determined considering the assumed dominant deformation mode (Fig. 4) and then added to the contribution of the floor systems. Symmetry with respect to the line of the lost column is assumed. The masonry panel adjacent to the affected bay is also explicitly modelled to capture realistic lateral restraint conditions, while the influence of the surrounding frame is introduced following the modelling scheme employed by Vlassis et al. (2008). Both solid infill and perforated walls (central opening of $1500 \times 1200 \mathrm{~mm}^{2}$ ) are considered, where in each case consideration is given to alternative detailing including and excluding an initial $80 \mathrm{~mm}$ gap between the top beam and masonry infill. The friction coefficient $\left(\tan \phi_{0}\right)$ for the frame-infill interface is taken as 0.35 following the recommendation in CSA (1994) for wet interface 
between masonry and steel. This represents the most unfavourable situation for energy dissipation purposes. As to the cohesion material parameter $C_{0}$, two limiting possibilities are presented: cohesion between frame and infill equal to the mortar cohesion within masonry panel (same $C_{0}$ as in Table 2) and reduced cohesion corresponding to a residual value given by $\tan \phi_{0^{\circ}} \sigma_{t 0}$ (where $\sigma_{t 0}$ is the tensile strength) emphasizing the frictional response of the frame-infill interface. The results obtained for the four arising cases in terms of the nonlinear static response and pseudo-static response are depicted in Figs. 10-13, where the bare frame response without infill is also shown, allowing the determination of the net contribution of masonry infill. Comparison between the results of the full cohesive frame-infill interfaces (Figs. 10-11) and frictional with reduced cohesion interfaces (Figs. 12-13) further highlights the potential contribution that this particular feature presents for frame-infill interaction. The maximum pseudo-static capacity and corresponding recorded deformations are summarised in Table 4, which can be directly compared to the floor system capacity excluding the infill as presented in Table 3. It is noted that the depicted range of resistance and deformation was largely limited by convergence issues, arising mainly from the use of softening cohesive models. Notwithstanding, as the scope of this research is mainly to emphasise the potential contribution of masonry infill at relatively small deformations, no mesh/time-step refinement was considered to overcome convergence issues. This is part of ongoing work, where the full response of masonry infill involving extensive cracking and associated softening is being investigated.

A substantial pseudo-static capacity is evident when infill panels are considered, even in the case of perforated walls. Deformed shapes for the case of full cohesive frame-infill interface without initial gap are presented in Fig. 14 for both solid and perforated panels. Contour plots of von Mises equivalent stress in the brick units within the walls illustrate a strut mechanism as frame- 
infill separation proceeds, this feature being more evident for the solid infill instance. In the case of solid infill, no damage is recorded within the panel whereas in the case of perforated walls, damage is visible around the opening. This is confirmed by the observation of interface damage contours in Fig. 15, where for solid infill there is only damage recorded at frame/infill interface level as opposed to the perforated wall where damage in the interface elements in the corners of the window is clearly visible.

\section{Robustness Assessment with Masonry Infill}

Using the results obtained for a single masonry panel, its effective contribution to progressive collapse resistance is evaluated as function of number of floors above the removed column. This is performed by multiplying the net capacities provided in Table 4 by the factor $\gamma$ introduced in (5). Furthermore, recalling (2) a factor $\alpha=0.28$ (Vlassis et al., 2008) is also introduced for work consistency. These values are then added to the pseudo-static capacity computed by Zolghadr Jahromi et al. (2013) with a full composite floor model at the corresponding deformation levels. The results for the case of cohesive frame-infill interface presented in Fig. 16 clearly show that masonry panels arrest progressive collapse at relatively small deformation, even in the most unfavourable case with perforated infill and gap between infill and frame, where the applied floor gravity load $742 \mathrm{kN}$ is indicated by a dashed line. On the other hand, if an interface with reduced cohesion is assumed only the cases without an initial gap stand to resist progressive collapse at small deformations, as shown in Fig. 17. As the number of floors above the removed column increases beyond 3, the robustness limit state is satisfied for both solid and perforated walls (without gap) at small deformations with limited damage in the framed structure. It is noted, however, that even the cases with a gap stand to enhance structural robustness via an additional contribution to the pseudo-static capacity in accordance with (7), though this would then be 
realised at a relatively large displacement $u_{\text {res }}$ which is comparable to the values provided in Table 3 for the case without infill panels.

\section{Conclusions}

This paper investigates the contribution of URM infill walls towards progressive collapse resistance under local damage scenarios. In particular, sudden peripheral column loss is considered for such a scenario within a ductility-centred robustness assessment framework.

High-fidelity simulation of masonry infilled frames is undertaken using advanced finite element procedures accounting for masonry nonlinear behaviour, actual frame-infill interface and nonlinear response of steel-concrete composite members and connections.

The results obtained considering both solid and perforated exterior walls and different conditions for the interface between URM infill and steel members show a significant contribution to robustness by infill panels subject to pushdown deformations. This is in line with previous research, where simple strut models were used to represent masonry infill. However, in this work it has been shown that the resistance to progressive collapse relies in great part on the frameinfill interaction rather than characteristic response of the masonry panel itself subject to internal damage. This is important because the former occurs at relatively small deformations safeguarding the structure from extensive damage. In this context, simple strut models allow the representation of damage evolution within the wall, but not the separation between frame and infill walls. Comparisons between the cases of fully cohesive and frictional with reduced cohesion frame-infill interface confirmed the importance of the actual interaction. This should be properly considered for robustness design and in assessment practice, and should therefore be subject to quality control during the construction process. 
The contribution of infill panel capacity at each floor within the performance based progressive collapse assessment framework is also explored. A decreasing contribution was found as the number of floors above the removed column is reduced, yet retaining a substantial capacity in the case of cohesive frame-infill interface even if only two floors are present above the removed column and one set of adjacent panels is therefore activated. Moreover, the fact that infill contribution significantly increases with the number of activated masonry panels is especially relevant, as the loss of ground floor columns constitutes a crucial initial failure scenario due to increased susceptibility to direct damage. This confirms that the contribution of infill masonry panels should be considered as a rational and efficient robustness enhancement factor typically found in many low-to-medium rise buildings. Ongoing work is aimed at extending the infilled frame analysis to higher damage levels within the walls (considering also non-uniform arrangement of infill walls) and investigating the potential influence of infill panels on the failure of structural components due to excessive masonry resistance forces. Consideration will also be given to different local damage scenarios, including the case of corner column loss which involves URM panels acting in perpendicular directions. Finally, experimental full scale static tests on one-storey two-bay steel frames with masonry infill under pushdown prescribed displacements will be conducted. These will make up for the lack of experimental results on infill frames under this specific loading condition and allow for an accurate validation of the numerical description for masonry infill frames under column loss scenarios.

\section{Acknowledgements}

The authors acknowledge the support provided by the Portuguese Foundation for Science and Technology (FCT) through the doctoral grant SFRH/BD/70935/2010 and by the of High Performance Computing (HPC) Services at Imperial College London. 


\section{References}

Cormie, D., Mays, G., Smith, P. (2009). Blast effects on buildings, Thomas Telford, London.

CSA. (1994). "Masonry design and construction for buildings - limit states design". CSA Standard S304.1-94, Canadian Standards Association, Rexdale, Ont.

Department of Defense. (2009). "Unified Facilities Criteria - Design of Buildings to Resist Progressive Collapse.” UFC 4 - 023-03, United States Department of Defense.

European Committe for Standardization. (2006). "Eurocode 1 Actions on Structures, Part 1-7: General Actions - Accidental Actions.” EN 1991-1-7, Brussels, Belgium.

Farazman, S., Izzuddin, B. A., Cormie, D. (2013). "Influence of Unreinforced Masonry Infill Panels on the Robustness of Multi-Storey Buildings.” J. Perform. Constr. Facil.,27(6), 673-682.

Gudmundsson, G. V., \& Izzuddin, B. A. (2010). "The sudden column loss idealization for disproportionate collapse assessment." The Structural Engineer, 88(6), 22-26.

Izzuddin, B. A. (1991). "Nonlinear Dynamic Analysis of Framed Structures." Ph.D. thesis, Dept. of Civil Engineering, Imperial College London, Univ. of London, London.

Izzuddin, B. A. (2009). "Recent Developments in Design-Oriented Assessment of Building Robustness." Trends in Civil and Structural Engineering Computing, pp 243-266. Saxe-Coburg Publications, Scotland.

Izzuddin, B. A. (2010). "Robustness by Design - Simplified Progressive Collapse Assessment of Building Structures.” Stahlbau, 79(8), 556-564.

Izzuddin, B. A. \& Nethercot, D.A. (2009). "Design-Oriented Approaches for Progressive Collapse Assessment: Load-Factor vs Ductility-Centred Methods". Don't Mess with Structural Engineers:Expanding Our Role, Austin, Texas, ASCE. 
Izzuddin, B. A., Vlassis, A. G., Elghaz1ouli, A. Y., and Nethercot, D. A. (2008). "Progressive collapse of multi-storey buildings due to sudden column loss—Part I: Simplified assessment framework.” Eng. Struct., 30(5), 1308-1318.

Jokhio, G. A. (2012). "Mixed Dimensional Hierarchic Partitioned Analysis of Nonlinear Structural Systems.” Ph.D thesis, Dept. of Civil \& Environmental Engineering, Imperial College London, London.

Jokhio, G. A., \& Izzuddin, B. A. (2013). "Parallelisation of nonlinear structural analysis using dual partition super-elements." Adv. Eng. Softw., 60-61, 81-88.

Khandelwal, K., \& El-Tawil, S. (2011). "Pushdown resistance as a mesure of robustness in progressive collapse analyis.” Eng. Struct., 33(9), 2653-2661.

Macorini, L., \& Izzuddin, B. A. (2011). "A non-linear interface element for 3D mesoscale analysis of brick-masonry structures.” Int. J. Numer. Methods Eng., 85(12), 1584-1608.

Macorini, L., \& Izzuddin, B. A. (2013). "Nonlinear analysis of masonry structures using mesoscale partitioned modelling.” Adv. Eng. Softw., 60-61, 58-69.

Macorini, L., \& Izzuddin, B. A. (2014). "Nonlinear Analysis of Unreinforced Masonry Walls under Blast Loading using Mesoscale Partitioned Modelling." J. Struct. Eng., 10.1061/(ASCE)ST.1943-541X.0000931, A4014002. 2014.

Mosalam, K. M. \& Günay, S. (2014). "Progressive Collapse Analysis of RC Frames with URM Infill Walls Considering In-Plane/Out-of-Plane Interaction.” Earthquake Spectra, In-Press, doi: http://dx.doi.org/10.1193/062113EQS165M.

Smith, P. P., Byfield, M. P., Goode, D. J. (2010). "Building Robustness Research during World War II". J. Perform. Constr. Facil., 24(6), 529-535. 
Tiago, P. \& Julio, E. (2010). "Damage of an RC Building after a landslide - inspection, analysis and retrofitting.” Eng. Struct., 32(7), 1814-1820.

Vlassis, A. G. (2007). "Progressive collapse assessment of tall buildings.” Ph.D thesis, Dept. of Civil \& Environmental Engineering, Imperial College London, London.

Vlassis, A. G., Izzuddin, B. A., Elghazouli, A. Y., and Nethercot, D. A. (2008). "Progressive collapse of multi-storey buildings due to sudden column loss-Part II: Application.” Eng. Struct., 30(5), 1424-1438.

Xavier, F. B., Macorini, L., Izzuddin, B. A. (2013). "Mesoscale Modeling of masonry Structures accounting for Brick-Mortar Interaction.” The Fourteenth International Conference on Civil, Structural and Environmental Engineering. Paper 71. Sardinia, Italy.

Xu, G., Ellingwood, B. R. (2011). "An energy-based partial pushdown analysis procedure assessment of disproportionate collapse potential.” J. Constr. Steel Res., 67, 547-555.

Zolghard Jahromi, H., Vlassis, A. G., Izzuddin, B. A. (2013). "Modelling Approaches for Robustness Assessment of Multi-Storey Steel-Composite Buildings.” Eng. Struct., 51(2013), 278-294. 


\section{List of Figures}

Figure 1. a) Building with masonry exterior cladding subjected to sudden column loss; $b$ ) governing phenomena in pushdown response of infilled frames.

Figure 2. Sudden column event with gravity load $P_{0}: a$ ) actual event; $b$ ) step load dynamic idealisation; c) static analysis using amplification factor $\lambda_{d}$ (Izzuddin et al., 2008)

Figure 3. a) Typical deformation to sudden column loss and different levels and structural idealisation for robustness assessment: $b$ ) sub-structure, $c$ ) only floors above removed column, $d$ ) single floor system and $e$ ) individual beams assemblage

Figure 4. Assumed dominant pushdown deformation mode accounting for floor and infill individual contribution

Figure 5. Simplified Dynamic procedure to obtain pseudo-static response (Izzuddin et al., 2008).

Figure 6. Graphical interpretation of infill dynamic residual capacity in the case of brittle static behavior: a) nonlinear static response, b) pseudo-static response

Figure 7. Mesoscale modelling of masonry: $a$ ) representative geometry: $b$ ) arrangement of zerothickness interface elements (Macorini \& Izzuddin, 2011)

Figure 8. Multi-dimensional coupling at frame-infill interface (reprinted from Macorini and Izzuddin 2014, ( ) ASCE)

Figure 9. $a$ ) Benchmark building; $b$ ) affected floor plan view; $c$ ) edge beam-to-column partial strength connection (Vlassis et al., 2008)

Figure 10. Results for solid infill with full cohesive interface: a) nonlinear static and $b$ ) pseudostatic response 
Figure 11. Results for perforated infill with full cohesive interface: a) nonlinear static and $b$ ) pseudo-static response

Figure 12. Results for solid infill with reduced cohesion interface: a) non-linear static and $b$ ) pseudo-static response

Figure 13. Results for perforated infill with reduced cohesion interface: a) non-linear static and $b$ ) pseudo-static response.

Figure 14. Magnified deformed shape with von Mises stress distribution in the solid elements $\left.\left(\mathrm{N} / \mathrm{mm}^{2}\right): a\right)$ solid infill without gap, $b$ ) perforated infill without gap.

Figure 15. Distribution of interface damage associated to mix-mode fracture (N/mm): a) Solid infill without gap, $b$ ) perforated infill without gap.

Figure 16. Variation of pseudo-static capacity with number of floors above the removed column at small deformations: full cohesive interface.

Figure 17. Variation of pseudo-static capacity with number of floors above removed column at small deformations: reduced cohesion interface.

Table 1 Material properties - composite frame

\begin{tabular}{|c|c|c|}
\hline Material & $\begin{array}{c}\mathrm{E} \\
\left(\mathrm{N} / \mathrm{mm}^{2}\right)\end{array}$ & $\begin{array}{c}\text { Strength } \\
\left(\mathrm{N} / \mathrm{mm}^{2}\right)\end{array}$ \\
\hline Structural Steel & 210,000 & 355 \\
\hline Concrete & 27,300 & 30 \\
\hline Reinforcement Steel & 200,000 & 460 \\
\hline
\end{tabular}


Table 2 Material properties - mortar joints

\begin{tabular}{|c|l|}
\hline Property & Value \\
\hline$k_{n}\left(\mathrm{~N} / \mathrm{mm}^{3}\right)$ & 80 \\
\hline$k_{t}\left(\mathrm{~N} / \mathrm{mm}^{3}\right)$ & 40 \\
\hline$\sigma_{\mathrm{t} 0}\left(\mathrm{~N} / \mathrm{mm}^{2}\right)$ & 1.20 \\
\hline$C_{0}\left(\mathrm{~N} / \mathrm{mm}^{2}\right)$ & 3.00 \\
\hline $\tan \phi_{0}-$ & 0.60 \\
\hline$\sigma_{c 0}\left(\mathrm{~N} / \mathrm{mm}^{2}\right)$ & 14.00 \\
\hline
\end{tabular}

Table 3 Floor pseudo-static capacity without masonry infill

\begin{tabular}{|c|c|c|c|}
\hline Model & $\begin{array}{c}\text { Pseudo-Static Capacity } \\
\left(P_{\text {Floor }}: \mathrm{kN}\right)\end{array}$ & $\begin{array}{c}\text { Maximum } \\
\text { Deflection } \\
(\mathrm{mm})\end{array}$ & $\begin{array}{c}\text { Capacity/Demand } \\
\text { Ratio }\end{array}$ \\
\hline Simplified Grillage & 744 & 376.5 & 1.040 \\
\hline Modified Grillage & 846 & 392.3 & 1.135 \\
\hline Detailed Grillage & 1057 & 359.5 & 1.420 \\
\hline Composite Floor & 1166 & 356.9 & 1.564 \\
\hline
\end{tabular}

Table 4 Results for two adjacent masonry infill panels subjected to pushdown deformation

\begin{tabular}{|c|c|c|c|c|}
\hline \multirow{7}{*}{$\begin{array}{c}\text { Frame-infill } \\
\text { interface }\end{array}$} & Case & $\begin{array}{c}\text { Infilled frame } \\
\text { pseudo- } \\
\text { static } \\
\text { capacity } \\
(\mathrm{kN})\end{array}$ & $\begin{array}{c}\text { Net masonry } \\
\text { panels pseudo- } \\
\text { static capacity } \\
\left(P_{\text {Panel }}^{\prime}: \mathrm{kN}\right)\end{array}$ & $\begin{array}{c}\text { Maximum deflection } \\
(\mathrm{mm})\end{array}$ \\
\hline \multirow{5}{*}{ Full cohesion } & Solid Panel w/o gap & 1260 & 1128 & 14.1 \\
\cline { 2 - 5 } & Solid Panel w/ gap & 524 & 420 & 10.8 \\
\cline { 2 - 5 } & $\begin{array}{c}\text { Perforated Panel } \\
\text { w/o gap }\end{array}$ & 673 & 578 & 14.7 \\
\cline { 2 - 5 } & $\begin{array}{c}\text { Perforated Panel w/ } \\
\text { gap }\end{array}$ & 474 & 388 & 30.0 \\
\hline \multirow{5}{*}{ Reduced cohesion } & Solid Panel w/o gap & 509 & 296 & 18.9 \\
\cline { 2 - 5 } & Solid Panel w/ gap & 238 & 72 & 23.8 \\
\cline { 2 - 5 } & $\begin{array}{c}\text { Perforated Panel } \\
\text { w/o gap }\end{array}$ & 303 & 113 & 26 \\
\cline { 2 - 5 } & $\begin{array}{c}\text { Perforated Panel w/ } \\
\text { gap }\end{array}$ & 286 & 198 & 14.8 \\
\hline
\end{tabular}



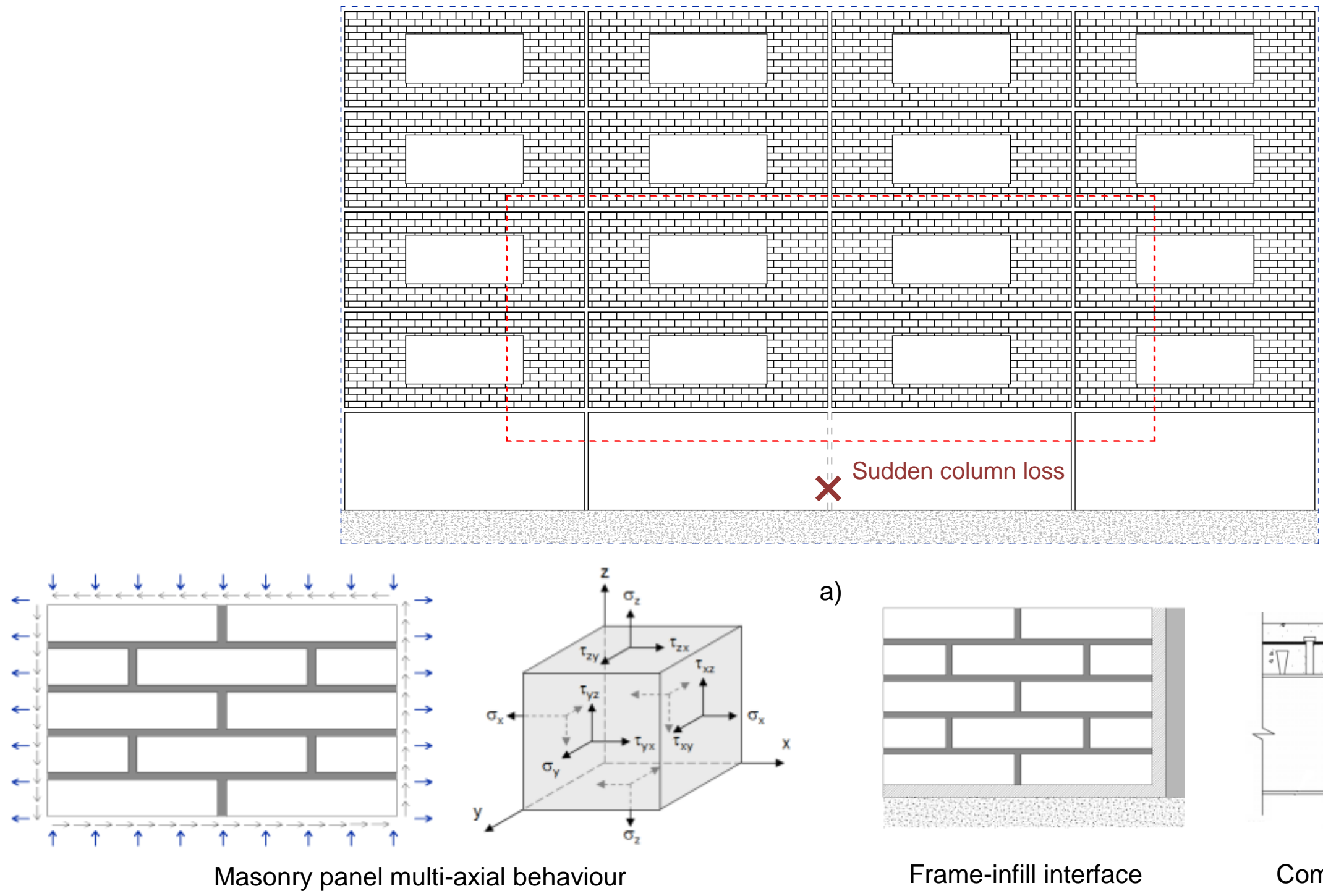

a)

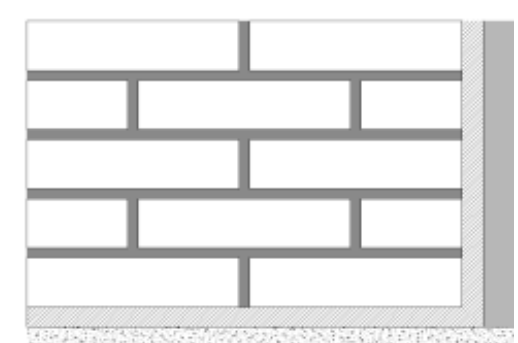

Frame-infill interface

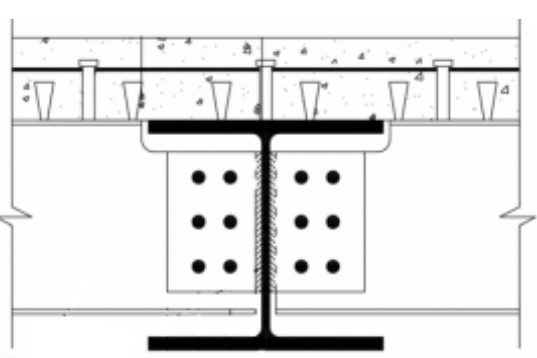

Composite joint response

b) 


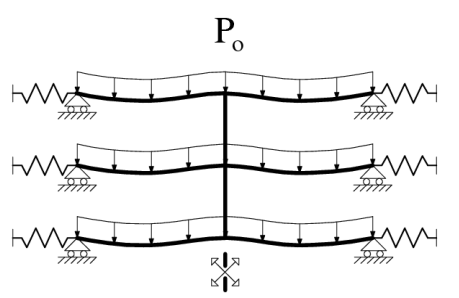

a)

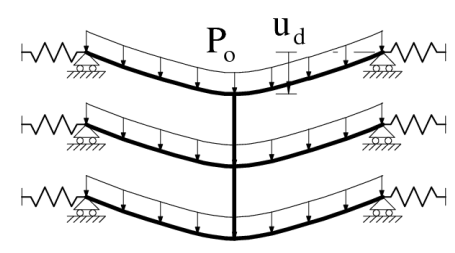

b)

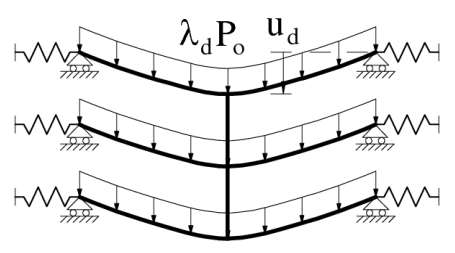

c) 
Translational/rotational boundary conditions

Sudden column loss

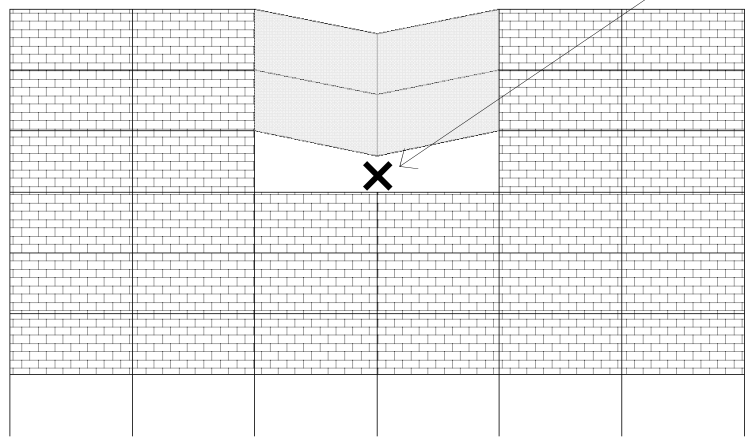

a)

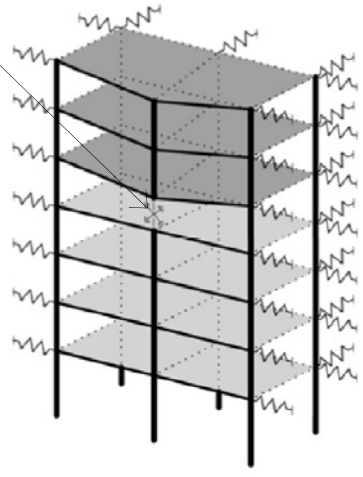

b)

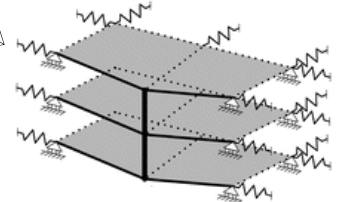

c)

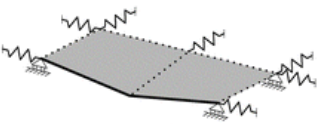

d)

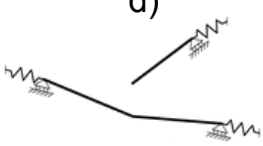

e) 


\section{Floor plate contribution}

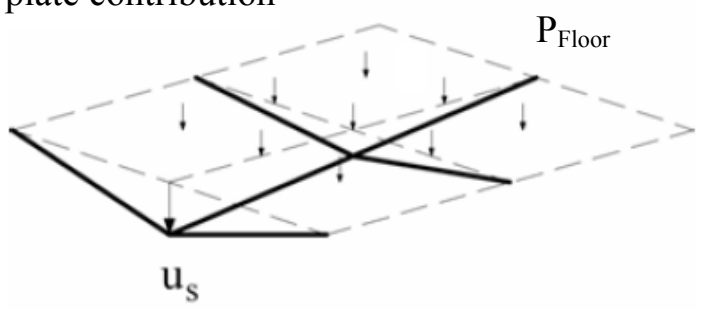

Assumed deformation mode

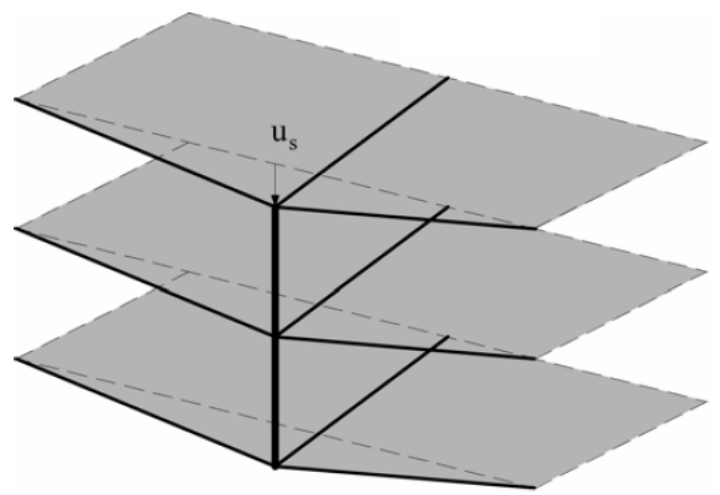

Infill panels contribution

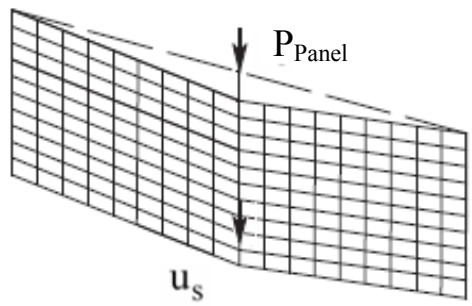




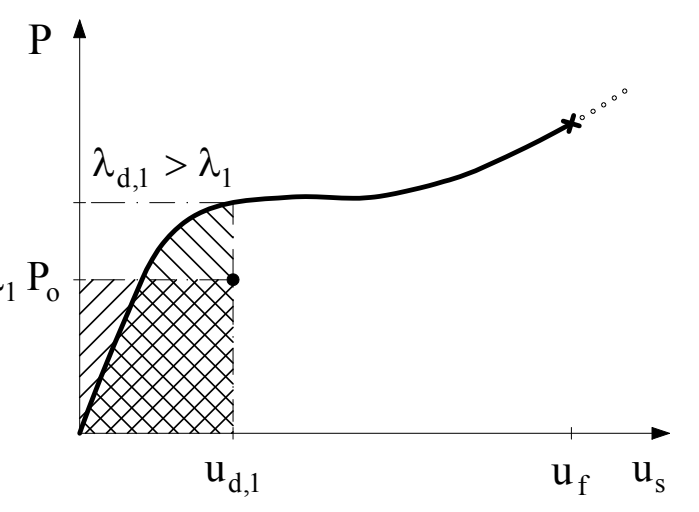

(a) Dynamic response $\left(\mathrm{P}=\lambda_{1} \mathrm{P}_{\mathrm{o}}\right)$

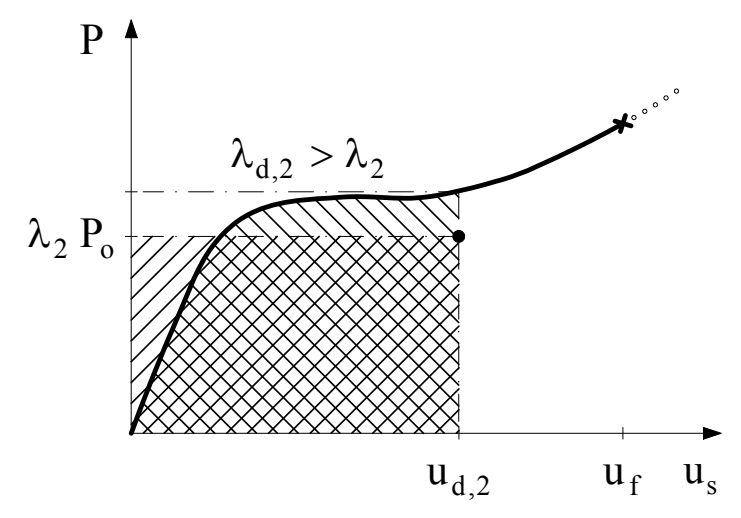

(b) Dynamic response $\left(\mathrm{P}=\lambda_{2} \mathrm{P}_{\mathrm{o}}\right)$

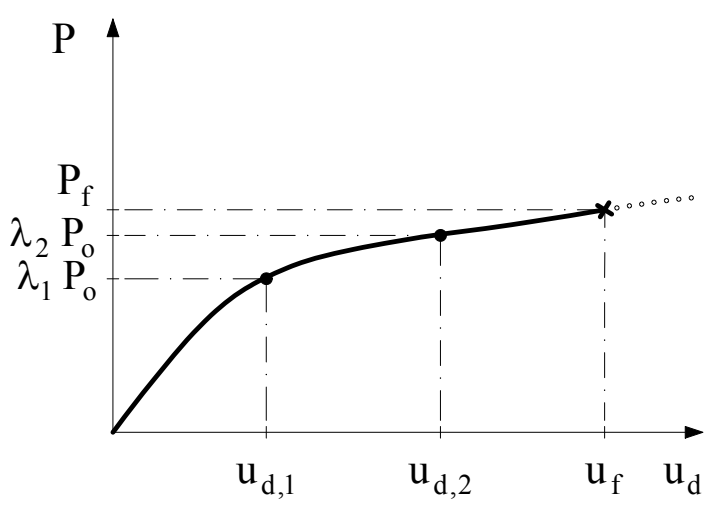

(c) Pseudo-static response 


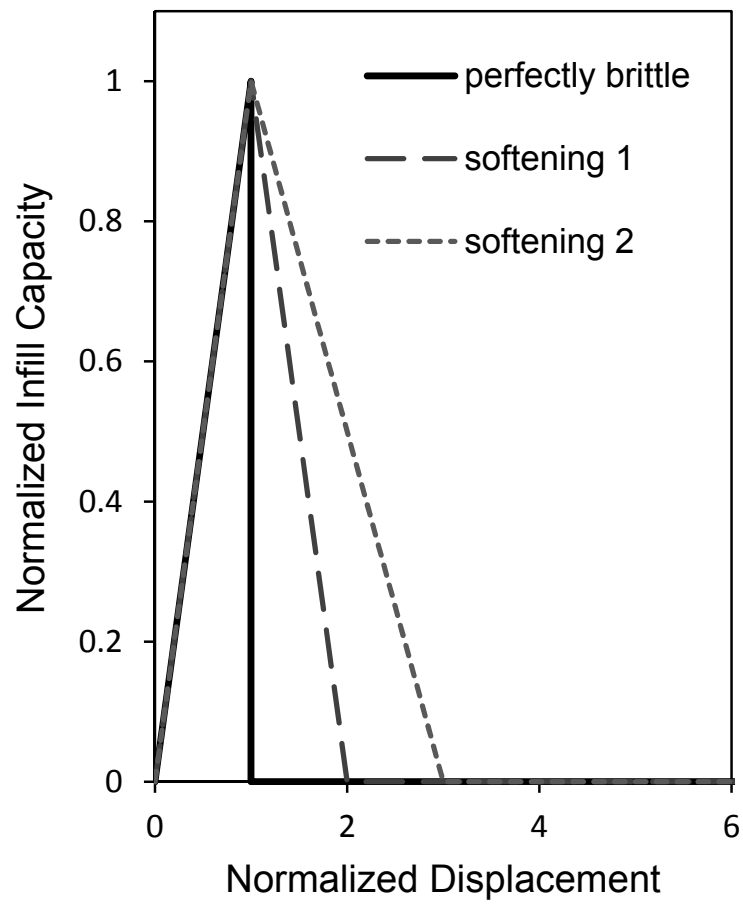

a)

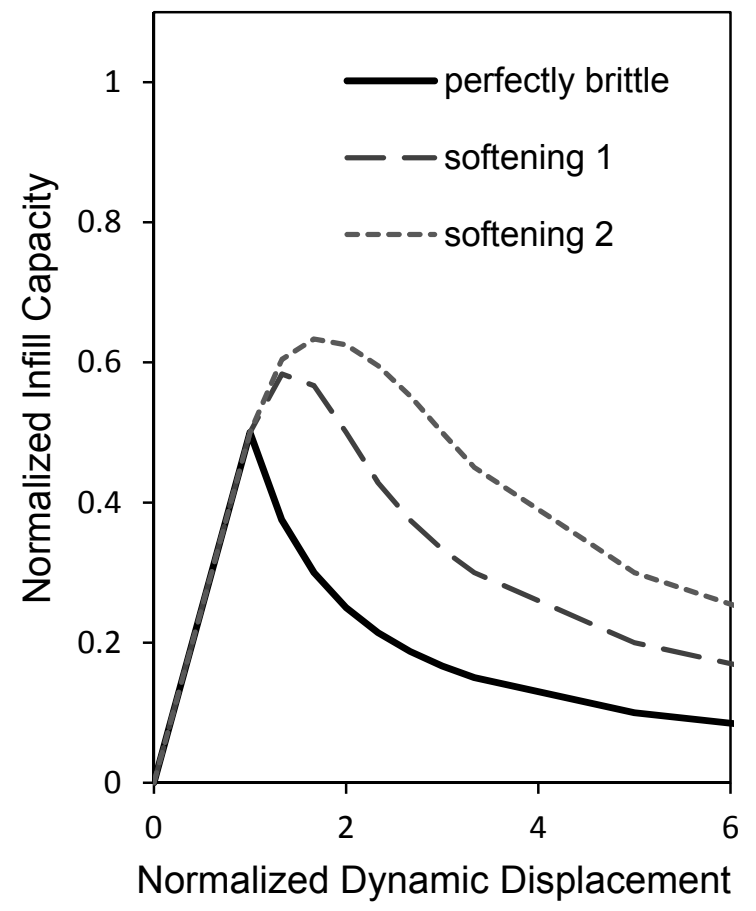

b) 


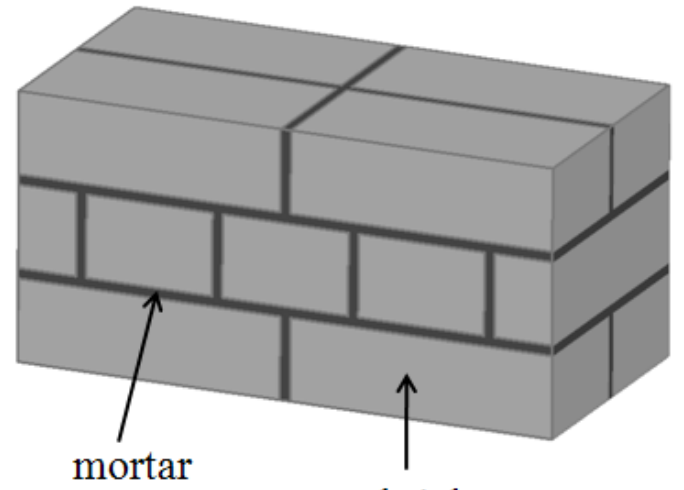

brick-mortar interface brick

a)

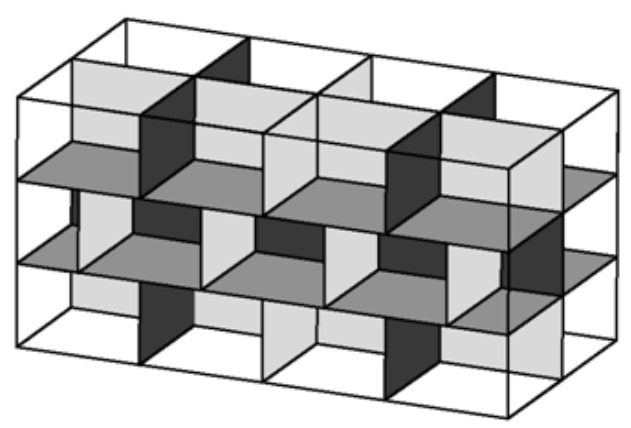

interface for brick-mortar bed joints interface for brick-mortar head joints interface for bricks

b) 


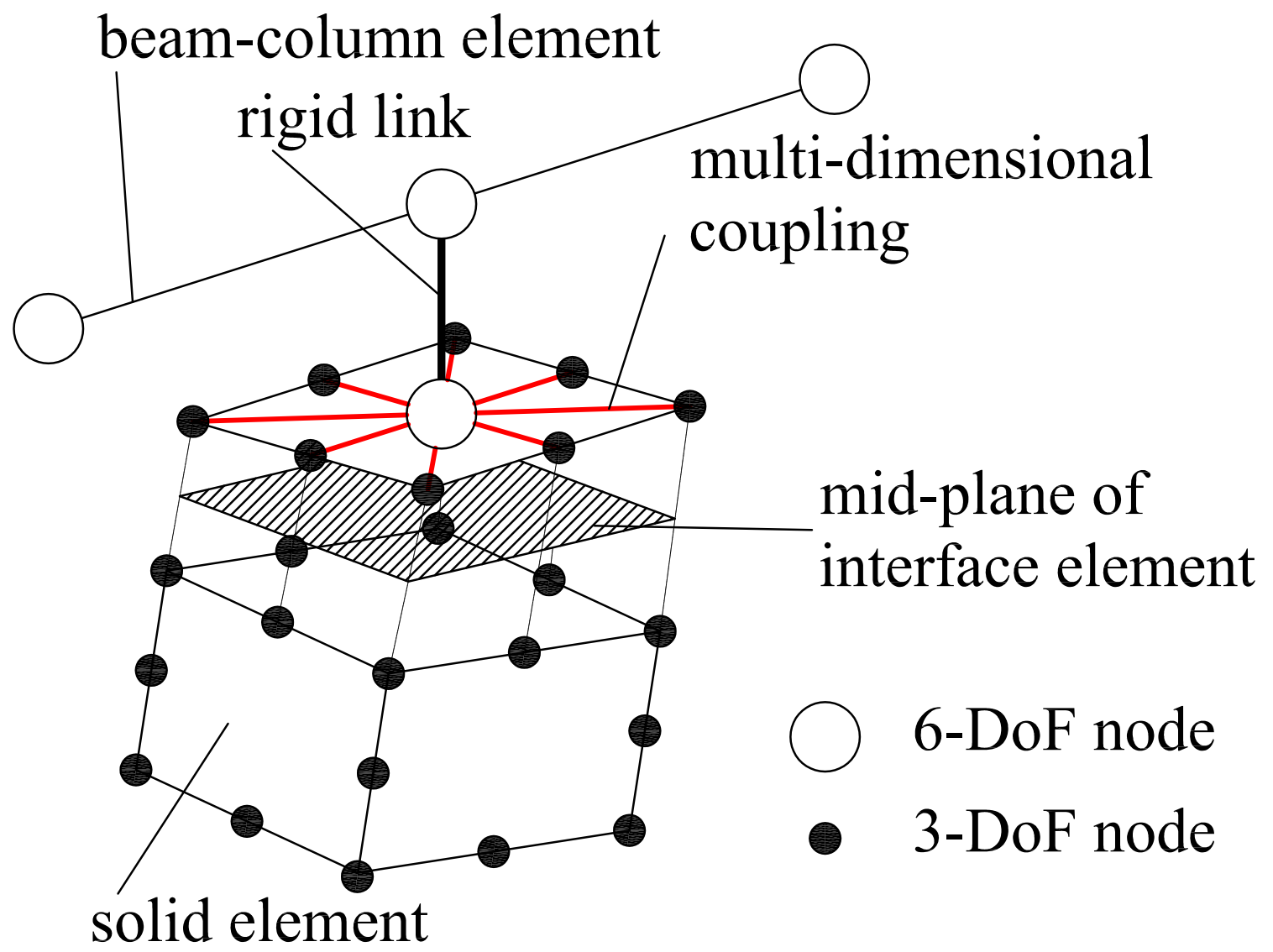




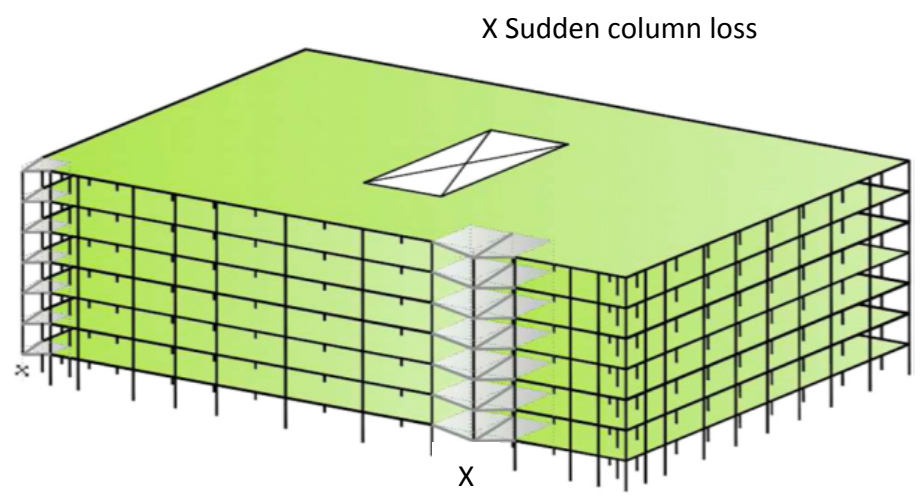

a)

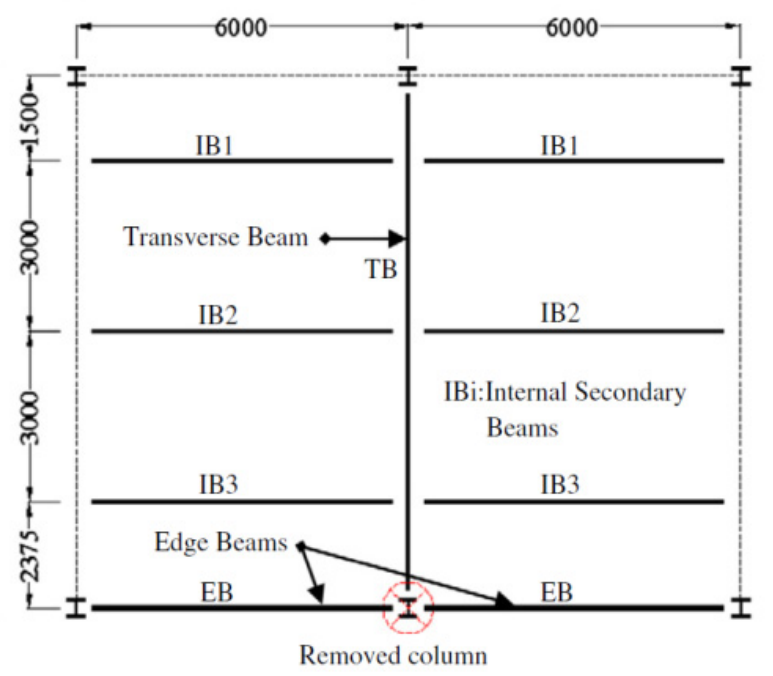

b)

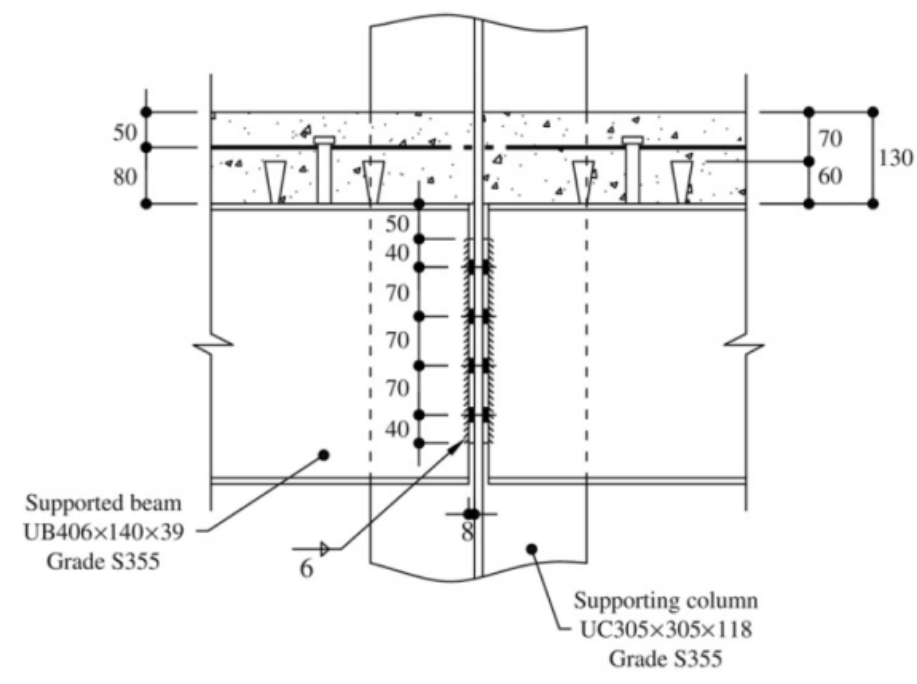

c) 


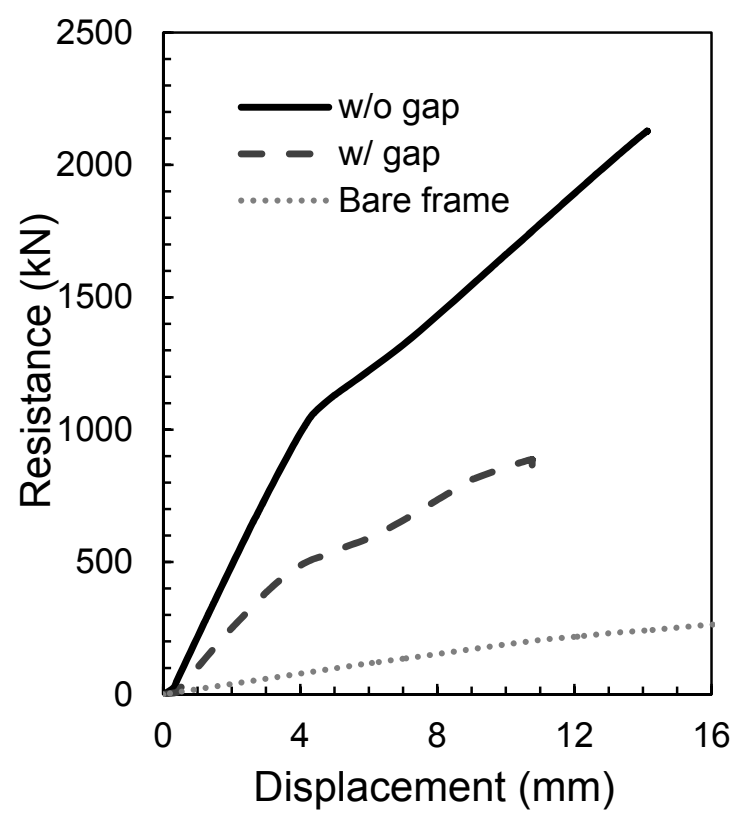

a)

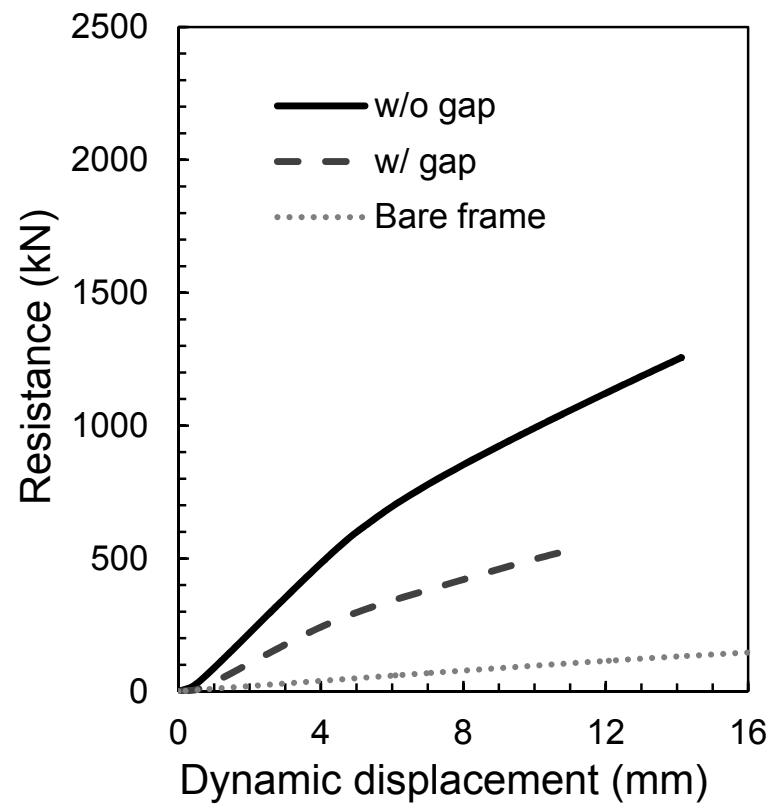

b) 


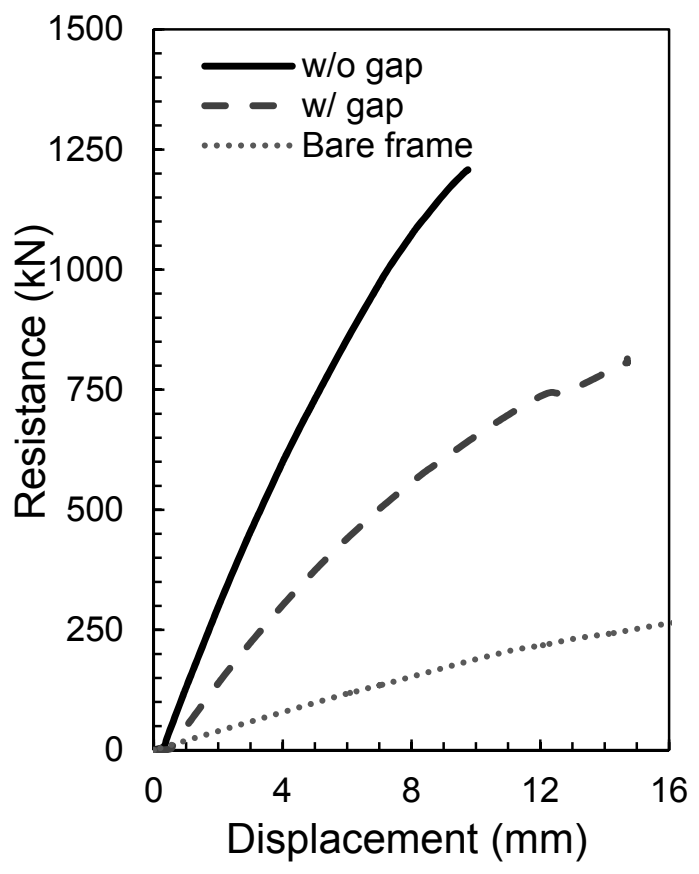

a)

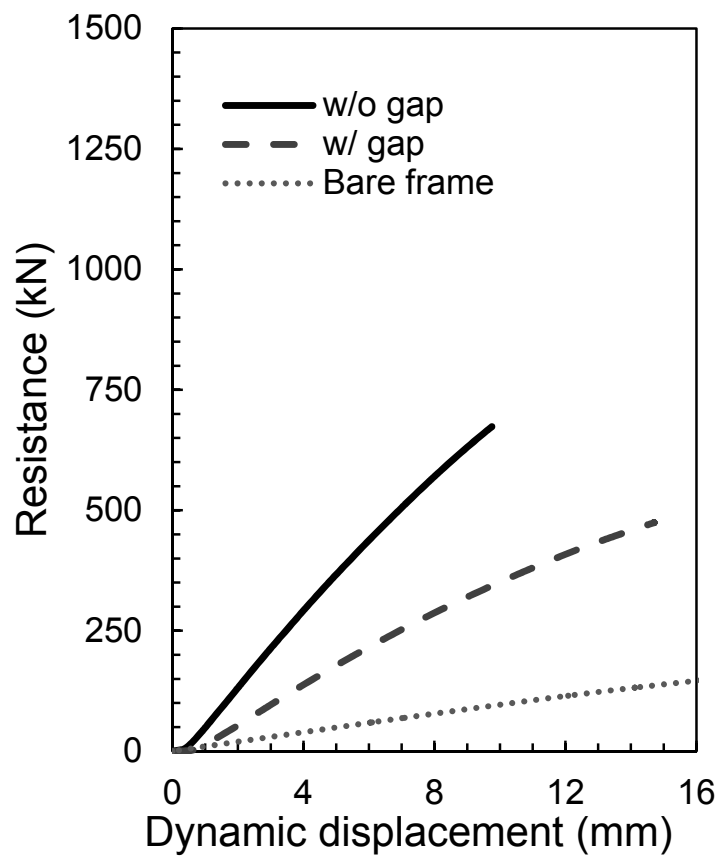

b) 


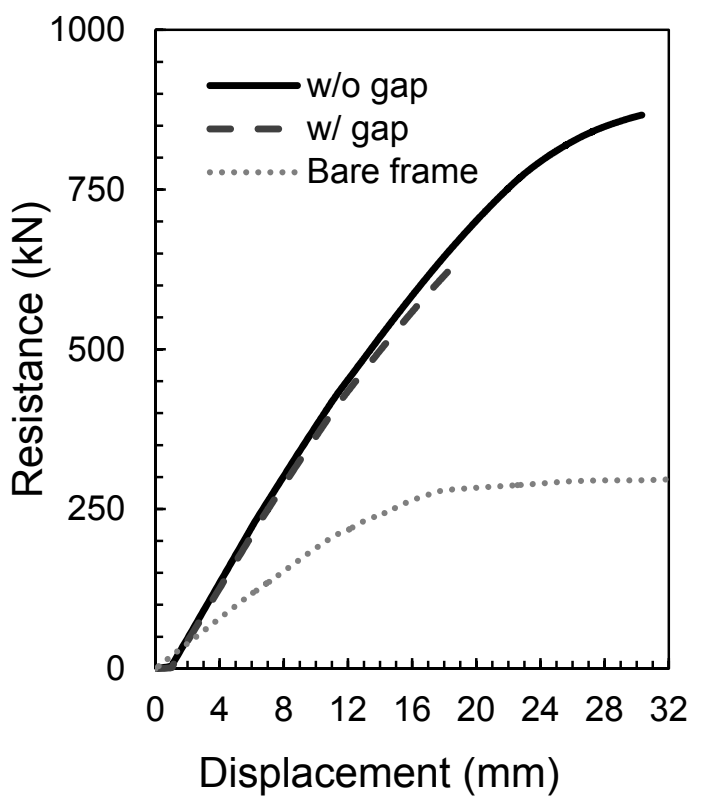

a)

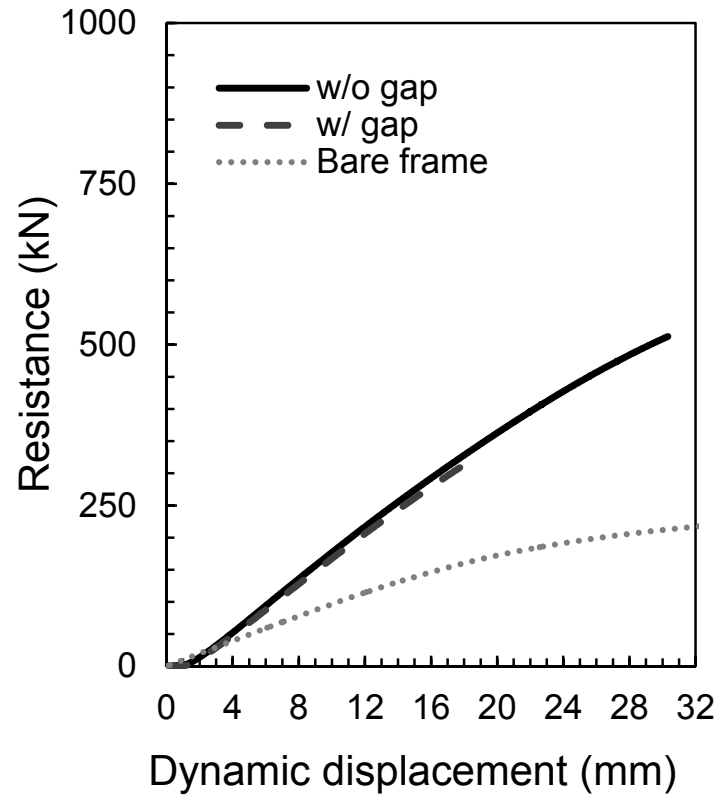

b) 


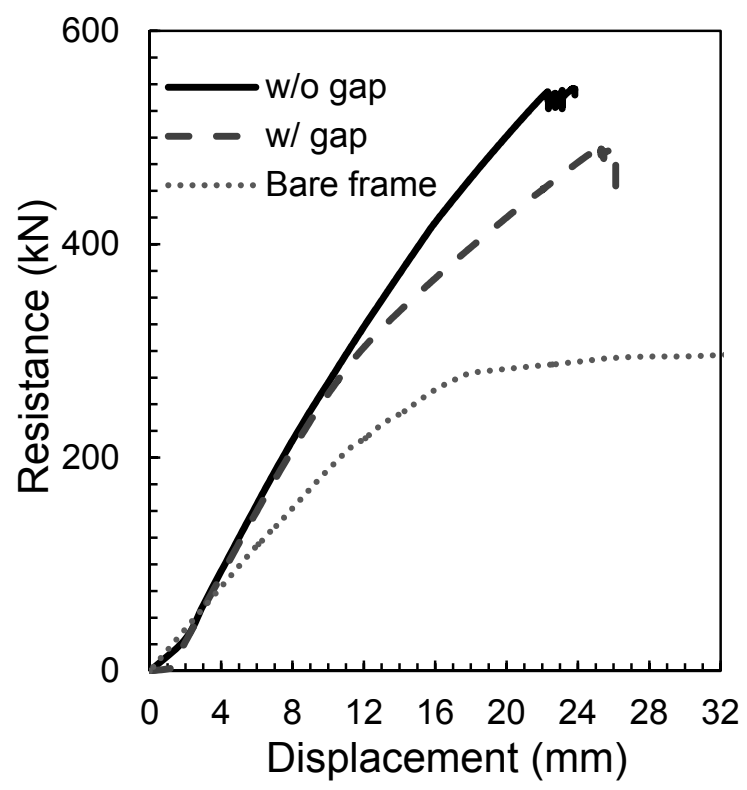

a)

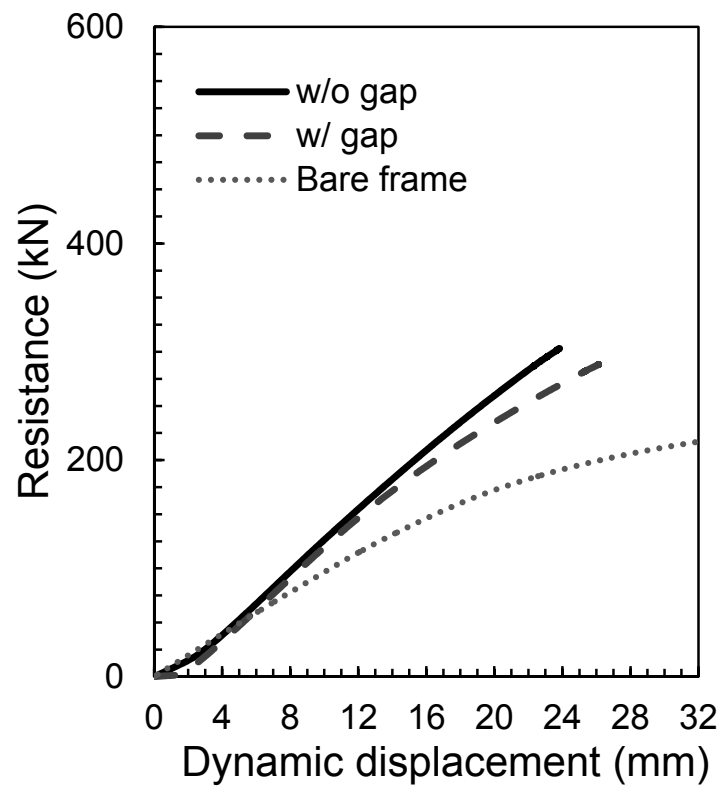

b) 


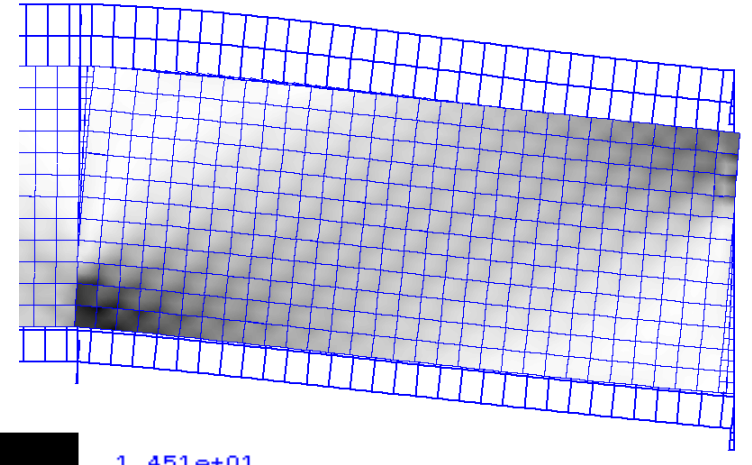

1. 451 e+01 $1.306 \mathrm{e}+01$ 1. $161 \mathrm{e}+01$ $1.015 e+01$ $1.015 e+01$ e+00 $7.253 e+00$ $5.803 e+00$ 4.352 e +00 $2.901 e+00$ $1.451=+00$ 1.451 e+00
$-9.537 e-07$ a)

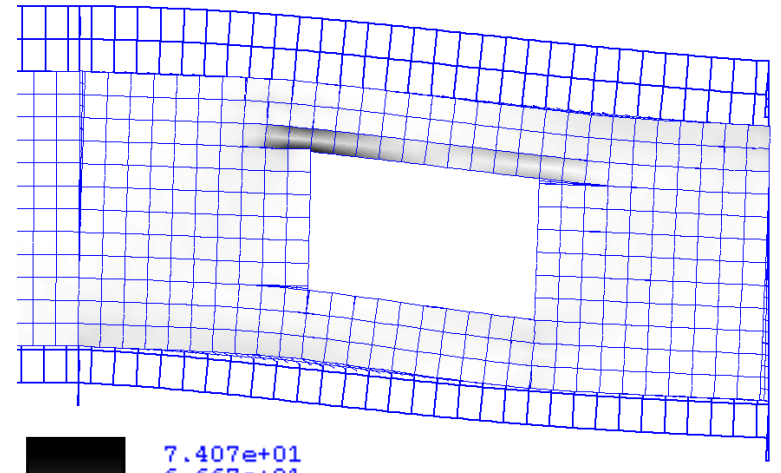

b)

$6.667 \mathrm{e}+01$

$5.926 \mathrm{e}+01$

5.185e+01

$4.444 \mathrm{e}+01$

3.704 e+01

2.963 e+01

2. $222 \mathrm{e}+01$

1. $481 e+01$

$7.407 €+00$

$0.000 e+00$ 


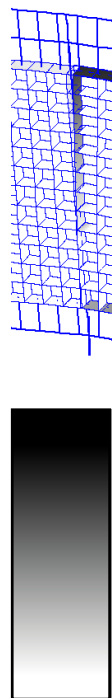

$1+1=1$

pese

4. $095 e-02$

3.686 e- 02

3. $276 e-02$

$2.867 e-02$

$2.457 e-02$

$2.048 e-02$

$1.638 e-02$

1. $228 \mathrm{e}-02$

8.190e-03

4.095e-03

0.000 e+00

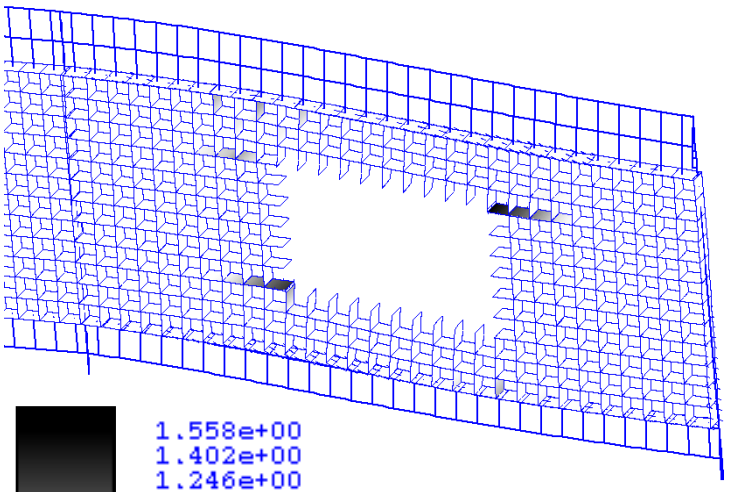

a)

$1.090 e+00$

9.346e-01

7.789e-01

6. 231 e-01

$4.673 \mathrm{e}-01$

3.115e-01

$1.558 \mathrm{e}-01$

0.000 e+00

b) 


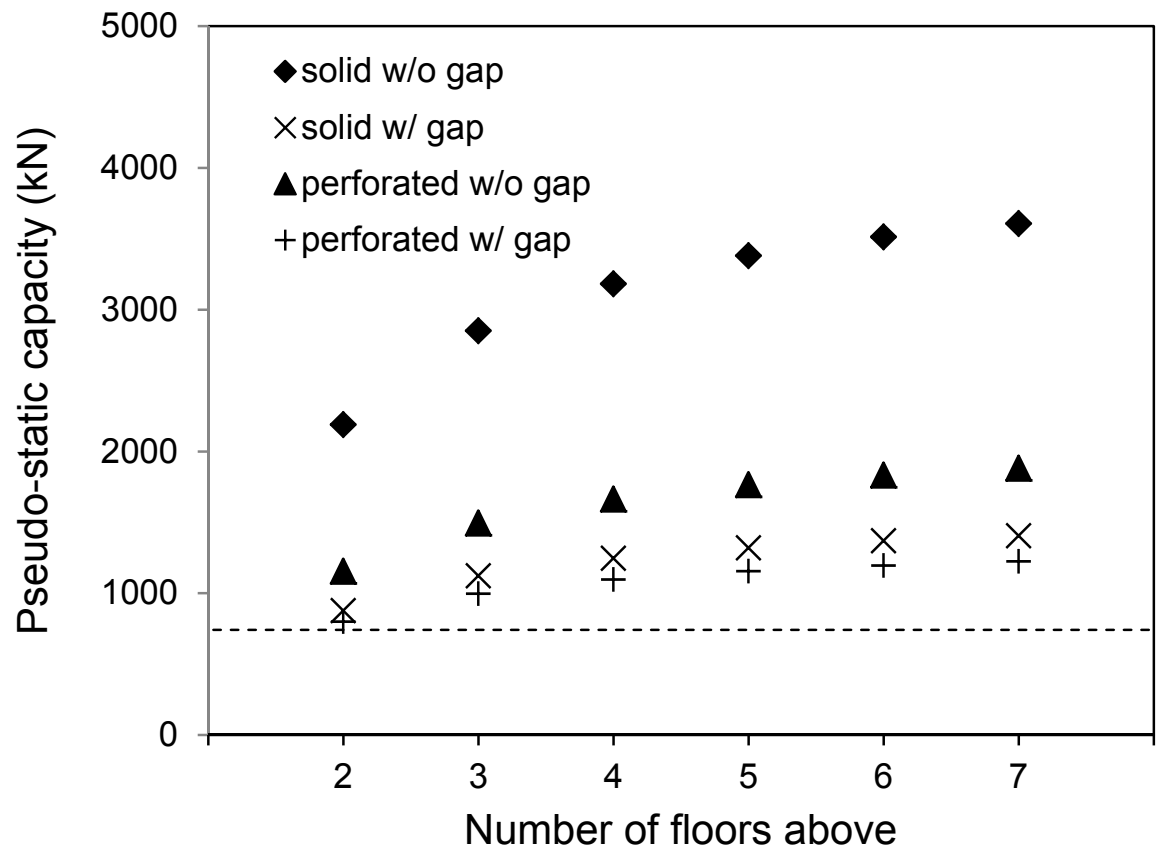




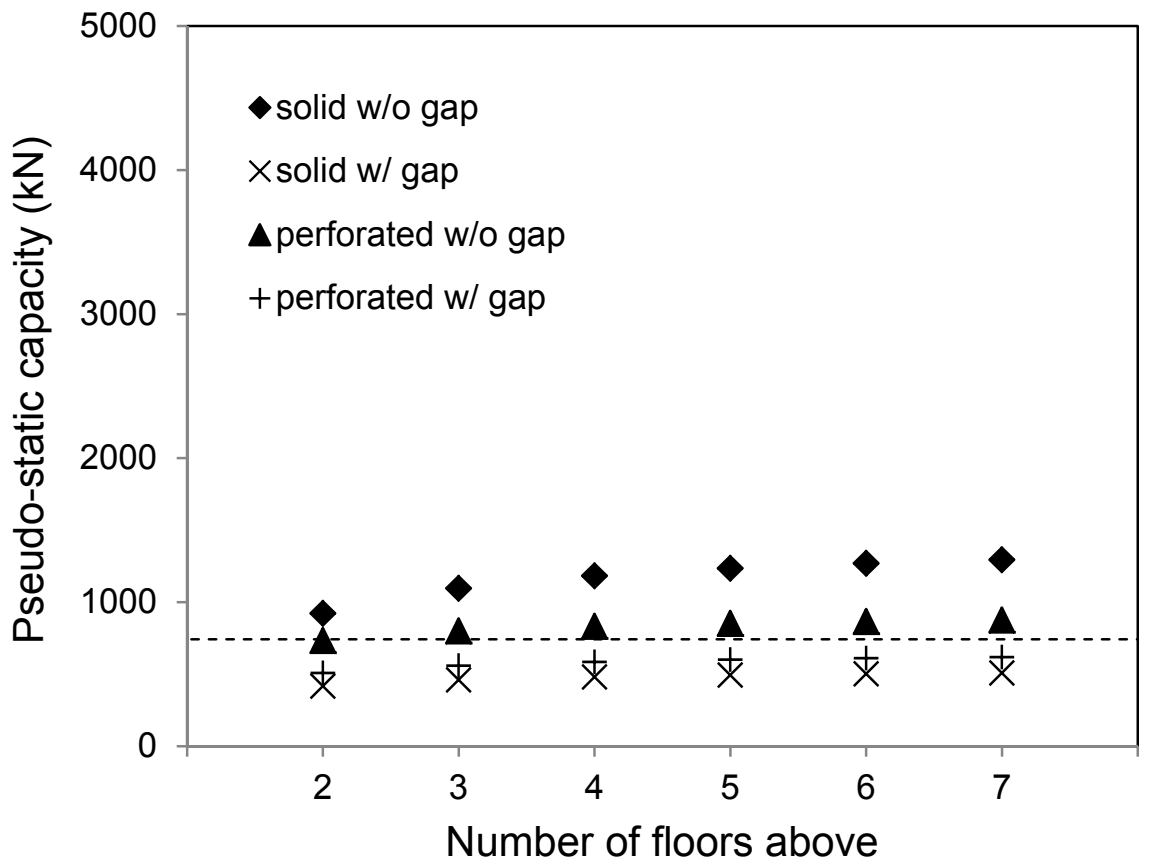

